\section{PC-053 NEW FORMULATIONS FOR THE TREATMENT OF ANTI-NEOPLASTIC AND RADIOTHERAPY-INDUCED MUCOSITES}

${ }^{1} \mathrm{G}$ Borciani, ${ }^{1} \mathrm{~F}$ Gradellini*, ${ }^{2} \mathrm{C}$ Polidori, ${ }^{1} S$ Manzini, ${ }^{1} \mathrm{G}$ Sommese, ${ }^{1} \mathrm{~L}$ Fares. ${ }^{1}$ Azienda Unità Sanitaria Locale - IRCCS di Reggio Emilia, Hospital Pharmacy, Reggio Emilia, Italy; 2University of Camerino, Pharmacology, Camerino, Italy

10.1136/ejhpharm-2019-eahpconf.134

Background The most common side effects of chemotherapy or radiotherapy are linked to systemic toxicity and toxicity towards rapidly growing cells. In the latter category, oral mucosites, which are quite disabling for patients, occur in $15 \%-40 \%$ of patients treated with conventional chemotherapy, in 70\%-90\% in those treated with TCSE and in $80 \%$ of those who receive radiotherapy for neck or head cancers. Because of pain and difficulty in eating due to mucositis, $16 \%-32 \%$ of these patients require recurrent hospitalisation. Obviously, this side effect bears heavily on the budget of the Italian healthcare system.

Purpose To deal with these challenges, hospital pharmacists working with other health professionals have developed new formulations.

Material and methods After researching the latest information on Galenic formulations in large literature databases, ${ }^{1}$ the hospital pharmacists evaluated currently available products and proposed new formulations. Once they prepared the formulations, they developed leaflets for each formulation to be given to the patient and caregiver. Treatments were provided for mucosites assigned a score from 0 to 3 on the WHO scale.

Results Of the formulations proposed, the hospital pharmacists adopted six solutions and one gel. Up to August 2017, the only one they produced was a formulation of lidocain and metilprednisolone. Subsequently, they added formulations of Ialuronate-Aloe (30\% of the formulations provided) and Misoprostole-artificial saliva (11\%), followed by Benzydamine and Supersatura (a solution containing sulphates and chlorides). In July 2018, Doxepin and Bicarbonate formulations were prepared, while the use of lidocain and metilprednisolone continued (36\%).

Conclusion The new formulations were introduced to maintain and increase oral hygiene, limit the risk of infections, moisturise the oral cavity and relieve pain, all things that were not achievable with the previous formulations.

\section{REFERENCES AND/OR ACKNOWLEDGEMENTS}

1. https://www.mascc.org/assets/Guidelines-Tools/mascc $\% 20$ isoo $\% 20$ mucositis $\%$ 20guidelines\%20paper\%206jun2014.pdf

2. http://www.salute.gov.it/portale/documentazione/p6_2_2_1.jsp? lingua $=$ italiano\&id $=2139$

3. http://www.cancernurse.eu/documents/EOCCGuidelinesv7.pdf

4. http://www.ukomic.co.uk/pdf/UK_OM_Guidelines.pdf

5. European Oncology Nursing Society(EONS), Oral Mucositis Guidelines, 2005.

6. http://www.palliativecareguidelines.scot.nhs.uk/media/42558/20170119-mouthcare.pdf

7. https://www.esmo.org/Guidelines/Supportive-and-Palliative-Care/Management-ofOral-and-Gastrointestinal-Mucosal-Injury

8. International Journal of Pharmaceutical Compounding (IJPC).

No conflict of interest.

\section{PC-054 ADDED VALUE FROM AN INFORMATION AND COMMUNICATION TECHNOLOGY- ASSISTED INTERVENTION IN A TOTAL PARENTERAL UNIT OF A PAEDIATRIC HOSPITAL PHARMACY}

${ }^{1} \mathrm{~K}$ Perdikouri, ${ }^{2} \mathrm{~L}$ Kouri ${ }^{*},{ }^{3} \mathrm{~K}$ Nikou, ${ }^{2} \mathrm{G}$ Pegkas, ${ }^{4} \mathrm{D}$ Gennimata. ${ }^{1}$ Spiliopoulio Hospital, Hospital Pharmacy, Athens, Greece; 'Paediatric Hospital 'Aglaia Kyriakou', Hospital Pharmacy, Athens, Greece; ${ }^{3}$ General Hospital of Chest Diseases 'Sotiria', Hospital Pharmacy, Athens, Greece; ${ }^{4}$ Korgialeneio-Benakio Red Cross General Hospital, Hospital Pharmacy, Athens, Greece

\subsection{6/ejhpharm-2019-eahpconf.135}

Background Given the need for customised total parenteral nutrition (TPN) formulations addressing infants and children, their preparation constitutes an everyday practice for paediatric hospitals' pharmacy departments, forming a time-consuming, complex and error-prone procedure.

Purpose To identify the benefits following the integration of an ICT-assisted intervention of prescribing and preparing 12 per day TPN formulations (365 days/year), in a 400-bed paediatric hospital.

Material and methods In order to achieve a thorough comparison, all steps of pre- and post-established procedures of TPN formulations' preparation were investigated in terms of time and human resources' consumption. Safety issues, medical staff's satisfaction and improved communication between the hospital pharmacy and actual point of care, were taken into consideration, as well.

Results During the first semester of 2018, the previous manually-held prescription procedure of ordering TPN formulations was incorporated into the main hospital pharmacy's information system (HPIS). This intervention resulted in a 35\% reduction in pharmacists' implementation time for controlling and finalising TPN prescriptions, while an overall $80 \%$ decrease in total preparation time, was observed. The elimination of the transcription step of the procedure decreased interpretation and calculation errors' occurrence. Legible prescriptions, entered at patients' bedside, are automatically transferred to the main HPIS, while all the information concerning the final TPN formulation is available even on doctors' mobile phones through Quick Response Codes labelling.

Conclusion Technology-enabled care interventions can assure faster and safer preparation of TPN formulations as well as eliminating unnecessary and error-prone steps in the procedure. Additionally, apart from saving crucial time for healthcare professionals, an essential information exchange is supported through the integration of patient medication records (kept at the HPIS) with the TPN record (kept at the compounding device's information system).

\section{REFERENCES AND/OR ACKNOWLEDGEMENTS}

None.

No conflict of interest.

\section{PC-055 CYTOTOXIC AGENTS: SKIN TESTS FOR THE DIAGNOSIS OF DRUG HYPERSENSITIVITY}

${ }^{1} \mathrm{P}$ Legendre*, ${ }^{1} \mathrm{AC}$ Bonnaure, ${ }^{2} \mathrm{R}$ Bellay, ${ }^{1} \mathrm{MA}$ Lester, ${ }^{1} \mathrm{PN}$ Boivin. ${ }^{1} \mathrm{CH} \cup$ Rennes, Pharmacie, Rennes, France; ${ }^{2} \mathrm{CH}$ Guillaume Regnier, Pharmacie, Rennes, France 
Background Skin tests have an important place in the diagnosis of hypersensitivity. Because of a lack of precise skin tests procedures, drug skin tests are often not carried out. However, they could help to determine the cause of hypersensitivity and help in the choice of therapeutic strategy. In our hospital, a dermatologist required us to produce skin tests with cytotoxic and anti-HER2 antibody agents (docetaxel, pertuzumab, trastuzumab) in order to evaluate the hypersensitivity of a patient who developed a photosensitive dermatosis after a second cycle of chemotherapy.

Purpose The aim of this project was to produce a feasibility study for the production of skin tests with these three molecules.

Material and methods A literature review was performed to find data about skin tests, and more particularly about safety and non-irritant drug concentrations. Because of a lack of data, we also decided to realise an investigation near the others hospital centres. Chemical tests were carried out such as the measure of the drug $\mathrm{pH}$ and the miscibility between the diluant and the medicine.

Results According to the literature, the $\mathrm{pH}$ drug must be between 6 and 9 to avoid skin injuries. By its acidic $\mathrm{pH}$, docetaxel could not be used to produce a patch test (non-diluated drug $\mathrm{pH}=3$, diluated with 0.9 per cent sodium chloride drug $\mathrm{pH}=4)$. The $\mathrm{pH}$ of the two other agents and of the diluant was acceptable $(\mathrm{pH}=7)$. In most of the publications, the excipient used for the preparation of patch tests was petroleum jelly. In cooperation with the doctor, we decided to produce a prick test with docetaxel, prepared by diluting the drug to $5 \mathrm{mg} / \mathrm{ml}$ in an aqueous solution of $0.9 \%$ sodium chloride. Concerning pertuzumab and trastuzumab, patch tests were obtained by realizing an homogeneous preparation, with a concentration of $30 \%$ in petrolatum.

Conclusion The literature deals mainly with a platinum agent, and more often with skin prick tests and intradermal tests. We were confronted with the difficulty of possessing poor data when facing the request of the dermatologist. Moreover, according to the literature, patch tests commonly reveal false negative results. This activity necessitates the development of a local thesaurus and an economic study.

\section{REFERENCES AND/OR ACKNOWLEDGEMENTS}

No conflict of interest.

\section{PC-056 PERFORMANCE ANALYSIS OF A FULLY AUTOMATED ONCOLOGY PHARMACY PRODUCTION: A 2018 UPDATE}

${ }^{1} S$ Leoni", 'MS de Meo, 'A Ortenzi, 'S Guglielmi, ${ }^{2}$ LL Borgiani, ${ }^{2} \mathrm{M}$ Federici, ${ }^{2} \mathrm{D}$ Paolucci, ${ }^{1}$ A Marinozzi. 'Ospedali Riuniti Ancona, Hospital Pharmacy, Ancona, Italy; ${ }^{2}$ Loccioni Group, Humancare, Ancona, Italy

10.1136/ejhpharm-2019-eahpconf.137

Background The aseptic compounding of injectable antiblastic drugs is centralised in the oncology pharmacy and, since 2014 , is performed by using a fully automated platform that enables control of the whole production process. The platform comprises a robotic system for fully automated preparation (APOTECAchemo), a supporting device for manual compounding (APOTECAps) and a workflow management software (APOTECAmanager). The production is mainly just-intime $(80 \%$ outpatient and $20 \%$ inpatient) and performed in a Class C cleanroom by seven pharmacy technicians and two pharmacists. The daily working time is from 8 am to $4 \mathrm{pm}$ (Monday-Friday).

Purpose The aim of this study was to analyse the performances of the fully automated oncology pharmacy production.

Material and methods The performances were analysed by means of the statistical tool of the APOTECA platform over a period of 9 months (January-September 2018). Productivity, dosage accuracy, precision and turnaround time were measured and compared between automated preparation with APOTECAchemo and manual preparation supported by APOTECAps.

Results Overall, 18524 preparations $(62.6 \%$ infusion bags, $26.3 \%$ syringes, $11.1 \%$ elastomeric pumps) were compounded with APOTECAchemo and 5272 preparations (52.3\% infusion bags, $46.8 \%$ syringes, $0.9 \%$ elastomeric pumps) with APOTECAps. In total, 82 different active ingredients were processed. Regarding dosage accuracy, APOTECAchemo showed better performances, with $96.6 \%$ of preparation with a deviation of $\pm 5 \%$ versus $93.0 \%$ of the manual compounding. Less than $1 \%$ of preparations presented a drug error exceeding $10 \%$. The turnaround time, calculated from the prescription time to the delivery time, was similar for both procedures. The average output amounts to 13.2 preparations/hour for APOTECAchemo and 15.0 preparations/hour for APOTECAps.

Conclusion The utilisation of the fully automated platform for managing the oncology pharmacy activities guarantees the possibility of measuring and controlling every single step of the whole production process. In-process controls, such as gravimetric control, barcode and photographic recognition, allow prompt corrective action in the case of deviations.

\section{REFERENCES AND/OR ACKNOWLEDGEMENTS}

No conflict of interest.

\section{PC-057 ECONOMIC IMPACT AFTER THE IMPLEMENTATION OF A RISK MATRIX IN THE PREPARATION OF CHEMOTHERAPY}

L López Esteban*, M Hijazi-Vega, R Diez-Fernández, R Gardón-Pérez, MÁ Esteban-Pérez, I Bueno-Florido, A Cidoncha-Berlanga, M Labrador-Paniagua, T Molina-García. Hospital Universitario de Getafe, Pharmacy Department, Getafe Madrid, Spain

\subsection{6/ejhpharm-2019-eahpconf.138}

Background National Guide of Good Preparation Practice for Medicinal Products in Hospital Pharmacy Departments (HPD) (2014) recommends the use of a risk matrix (RM) to assess the risks during the preparation and ensure the quality of the finished product. The RM evaluates several topics: preparation process, administration route, safety profile, number of preparations per batch and microbiological contamination susceptibility.

According to the level of risk assigned by the RM, storing conditions and expiry dates for each preparation may change from labelled information and extended stability studies. Thus, in most cases, after implementing a RM in the preparation of medication at the HPD, there is a shorter in-use expiry date both for the final product and for the vial leftovers. Shorter expiry dates could lead to a greater waste of product, and therefore, greater economic losses.

Purpose We aim to evaluate the economic impact in the preparation of chemotherapy after implementing the RM in our pharmacy.

Material and methods Prospective observational study. 